\title{
Use of Endodontic Cores for Rigid Screw Retention of the Natural Dentition to Dental Implants by Means of Fixed Partial Prostheses for the Atrophic Mandible: Long-Term Clinical Results
}

\author{
Cimara Fortes Ferreira ${ }^{1 *}$, Antonio Carlos Cardoso ${ }^{2}$, Rafaella Cid ${ }^{3}$, Joao Gustavo Oliveira de Souza ${ }^{3}$, Russell \\ Anthony Wicks ${ }^{4}$
}

${ }^{1}$ Discipline Periodontics, University of Tennessee Health Sciences College of Dentistry, USA

${ }^{2}$ Department of Prosthodontics, Federal University of Santa Catarina, Brazil

${ }^{3}$ Department of Implant Dentistry, Federal University of Santa Catarina, Brazil

${ }^{4}$ Department of Prosthodontics, University of Tennessee Health Sciences College of Dentistry, USA

*Corresponding author: Cimara Fortes Ferreira, Associate Professor, Director of Implant Dentistry/Department of Prosthodontics, University of Tennessee School of Dentistry, Dunn Dental Building, 875 Union Avenue, Memphis, TN38163, USA.

Received Date: 24 July, 2018

Published Date: August 06, 2018

\begin{abstract}
Purpose: Describe a technique to restore a partially edentulous patient with limited bone for an implant-supported bridge.

Material and methods: Two clinical cases are described using a lingual screw technique for retrievability of implant-tooth supported bridges.

Results: A 7 and 10-year clinical follow-ups showed health for the implants and clinical stability of the surrounding tissues in both cases presented.

Conclusion: The authors suggest this treatment option to be limited to cases where the dental implant placement is not possible; as in the cases reported.
\end{abstract}

Keywords: Tooth-implant supported prostheses; Fixed bridges; Prosthetic connections; Tooth-implant supported rehabilitations; Tooth-implant splinting

\section{Introduction}

Implant-supported prostheses have been first choice for treating lost teeth. However, there are challenging cases that only reach resolution by exploring unconventional options. In order to overcome specific shortcomings, tooth-implant supported prostheses have shown to be a predictable treatment option. The most significant difference between an implant-supported prosthesis, when compared to a tooth-supported, is the absence of a periodontal ligament (PDL). This anatomic structure is responsible for tooth movement, shock absorption, and proprioception [13]. Implant-supported prostheses have the same limitations and challenges as the tooth-supported prostheses [4,5], which do not have the benefit of a PDL. Therefore, splinting an implant to a tooth may indirectly increase the proprioception of the implant and, consequently, protect the stomatognathic system.

There is no consensus regarding the use of this treatment option [4-12]. Ericcson et al. [11] was the first researcher to study this treatment option in 10 partially edentulous patients. Rigid connectors were used in 6 , and semi-rigid in 4 patients. The results showed a $3 \mathrm{~mm}$ marginal bone loss around the implant of 1 patient treated with a rigid connector. For another patient treated with 
non-rigid connectors, there was intrusion of the mesial portion of the tooth-supported segment in relation to the implant-supported portion after 3 months in function.

Most problems that occur in the tooth-implant union have been attributed to the difference in the mobility between the two abutments [4-13]. Complications may occur in this type of treatment, which include: implant abutment fracture, screw fracture, prosthetic fracture, tooth intrusion, marginal bone loss and loss of osseoinegration [3-16].

This treatment option has the advantage of maintaining indirect tactile and reflex sensitivity of the dental implant, due to the presence of the periodontal ligament of the abutment tooth. The proprioceptive mechanism allows the body to detect light force sensations through the teeth. This is an important mechanism in the protection of the structures of the stomatognathic system during function [4-17].

Several authors have questioned non-rigid connectors used to unite teeth with dental implants [3-19]. The use of screw retention has been advocated in both the implants and abutment teeth for these prostheses [14-20]. The advantages of cemented restorations is the ease of the technique, and possible improvements in strength and esthetics [5-21].

In a retrospective study, the clinical results of more than 3,000 implant supported bridges attached to natural teeth have been reported. Restorations fitted with locking screws promoting rigidity of the connectors were used. Only $0.3 \%$ of abutment teeth showed signs of intrusion, and always in combination with a fracture of the locking screw [5]. The objective of the present study is to report the follow-up of 2 cases; one after $8 \frac{1}{2}$ years and the other after $6 \frac{1}{2}$ years in function, and the technique to manufacture these prostheses.

\section{Case Reports}

\section{Clinical case 1}

A 50 years old female presented to the Center of Continuing Education and Research in Dental Implants (CEPID) at the Federal University of Santa Catarina, Florianopolis, SC, Brazil, for rehabilitation of the lower left quadrant. Clinical exam showed absence of teeth \#18, 19 and \#20 and presence of a residual root, which was the result from a fractured crown \#21.

Diagnostic casts were mounted on the articulator for treatment planning. Two external hexed 3.75 x $8.5 \mathrm{~mm}$ (Conexao Implant System, SP, Brazil) implants were placed for sites \#18 and \#19. Root canal therapy was conducted for tooth \#21. After the period of osseointegration, the second stage surgery was performed and 1 mm collar multi-unit abutments were placed and secured with 35 $\mathrm{N}$ cm torque.

The root of tooth \#21 was prepared and an impression was taken with polyvinyl siloxane (3M ESPE Express, SP, Brazil) for a cast post and core. The impression of the multi-unit abutments was made with an open tray technique. In addition, an alginate impression of the upper arch antagonists and an inter-occlusal record was obtained. The record was made using plastic cylinders secured to the multi-unit abutments and splinted with self-cured acrylic resin. A portion of the same acrylic resin was added between the cylinders and the patient was asked to bite until the teeth were in contact with the acrylic resin. The record was removed from the mouth and placed on the working model. The models were mounted on a semi-adjustable articulator and sent to the laboratory for fabrication of the prosthesis.

A gold post and core was fabricated and cemented with zincphosphate cement (SS White, Rio de Janeiro, RJ, Brazil) to tooth \#21. Next, Duralay acrylic resin (Reliance Dental MFG Company, Illinois, EUA) was used as a try-in for the metal infrastructure for the PFM crown. The core of tooth \#21 presented an opening drilled using a threading kit (Attachment System Set Screw CNG®). The objective of the lingual opening was to receive a screw-retained infrastructure. The kit consists of the burs, the screw housing tube for thread formation, a peg male used for fabricating the threads on the system set screw, in addition to drivers and manual precision milling devices. The sculpture is concluded with the wax pattern for later inclusion and casting. The peg male is used again for cleaning and final machining of the threads (Figure 1).

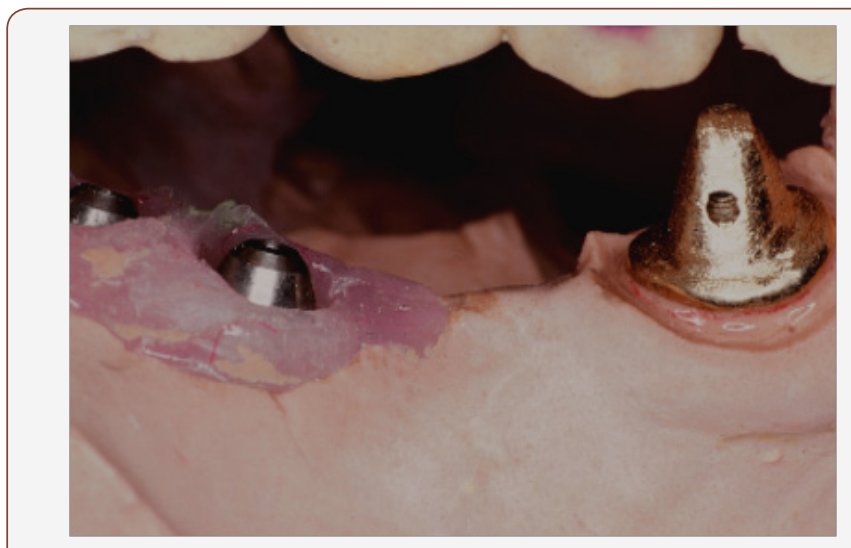

Figure 1: Lateral lingual view of the lower left arch tissue-cast. Note the transferred position of the multi-unit abutments for the implants \#18 and \#19 and the fabricated gold alloy cast core with lingual screw access for tooth \#21.

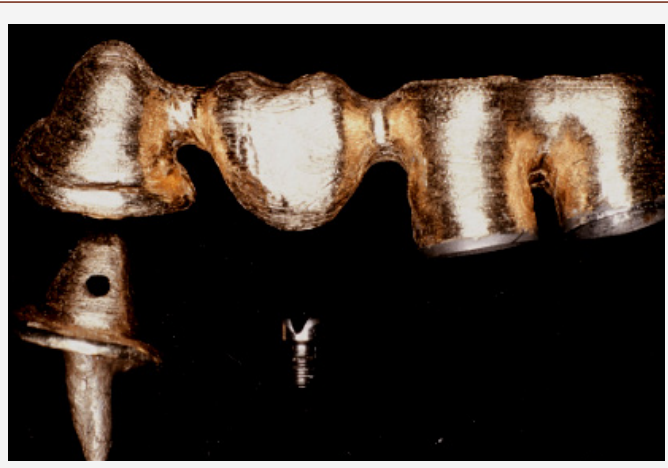

Figure 2: Lateral view of the cast gold alloy infra-structure. Note the presence of the screw access hole in the post and core. Two gold cylinders for implants \#18 and 19 were cast to a pontic for \#20 and the coping for tooth \# 21.

Gold cylinders were used over multi-unit abutments. A framework of the same alloy was fabricated splinting the implant and tooth with a pontic for \#20 (Figure 2). The infrastructure was tried in the mouth (Figure 3) showing acceptable adaptation. After 
selecting the shade, porcelain application was completed (Figure 4).

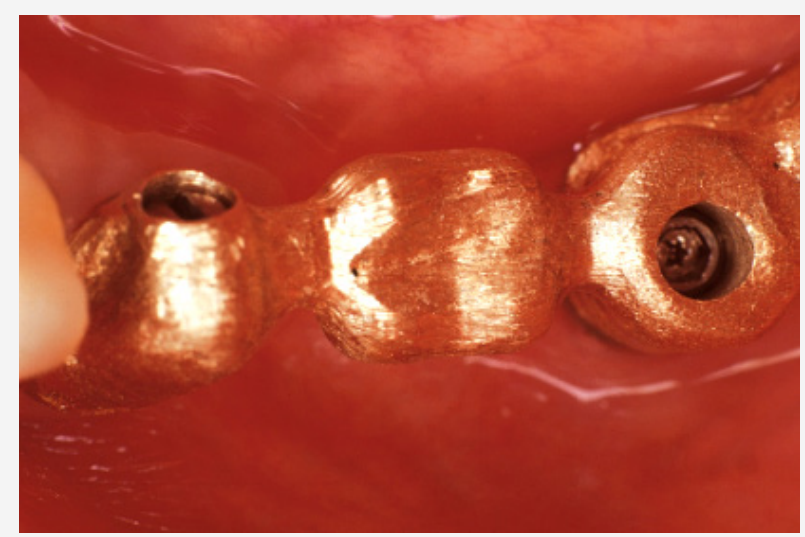

Figure 3: Occlusal view of the metallic infra-structure at try-in with occlusal access screw holes for implant \#19 and lingual access hole for tooth \#21.

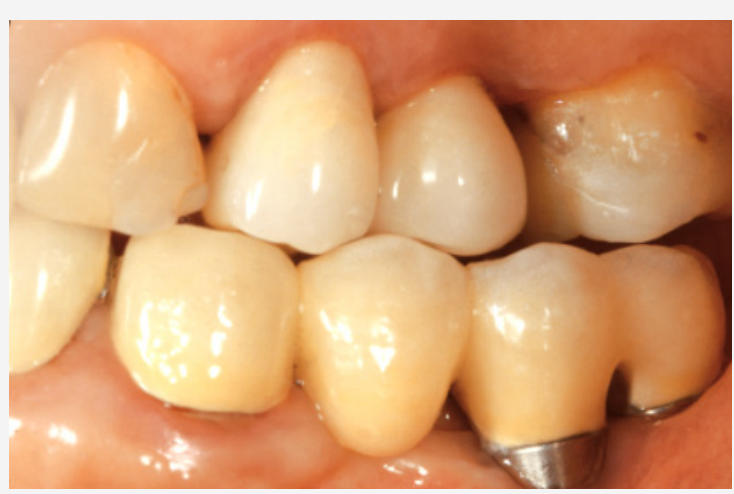

Figure 4: Clinical lateral right view of the implant-tooth supported screw-cement retained prosthesis immediately post-insertion.

The prosthesis was placed and occlusal contacts checked by means of articulating paper (Accufilm II Parkell, Farmingdale, USA) secured with Miller forceps. A fine-grain tapered diamond bur (Intensiv SA, Switzerland) was used for adjustments needed. The few areas of wear were smoothed with Sof-Lex polishing discs (3M ESPE, SP, Brazil) and polished with felt diamond discs (FGM, Joinville, SC, Brazil) and diamond paste (Diamond Excel, FGM, Joinville, SC, Brazil) mounted on the mandrill of a slow-speed contra-angle handpiece.

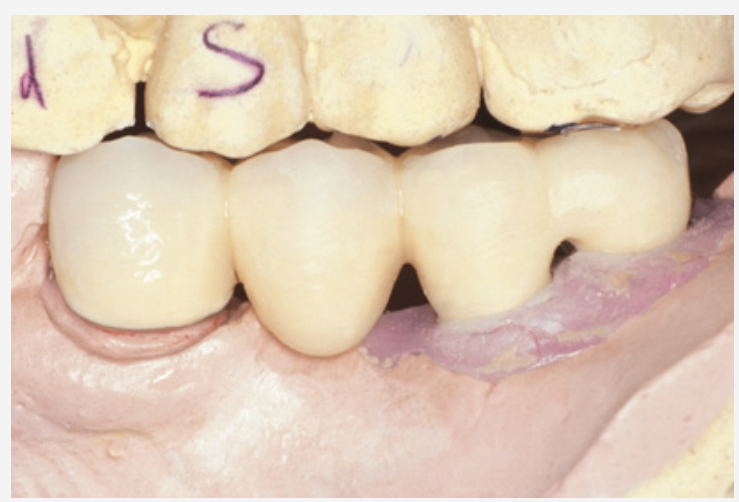

Figure 5: Try-in of the porcelain and occlusal adjustment
Importantly, the metal infrastructure of tooth \#21 was screw-retained to the core on the lingual aspect and the implantsupported prosthesis was screwed to the abutments on the occlusal aspect. Two hexed screws were used for the multi-unit abutments. However, a slotted screw was used for tooth \#21 in order to reduce the bulk of the prosthesis on the lingual aspect. Laboratory (Figure 5) and clinical pictures were taken post-placement (Figure 4).

A 10-year clinical follow-up exam showed health for the implants \#18 and 19 and the surrounding tissues. Tooth \#21 presented with slight gingival inflammation (Figure 6).

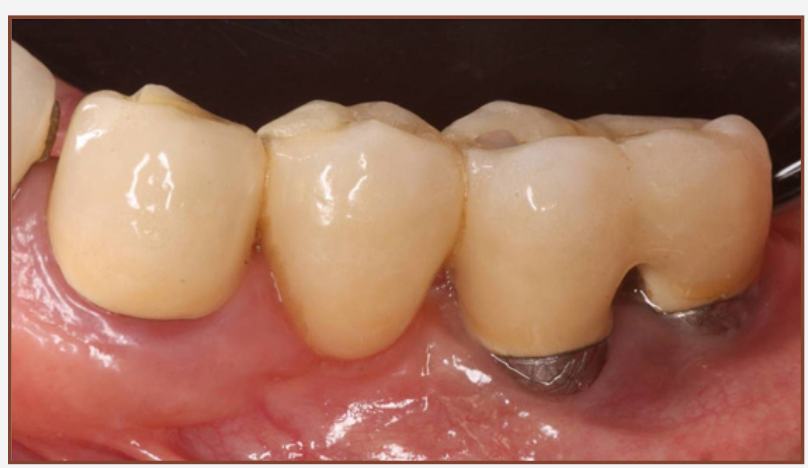

Figure 6 : Clinical lateral right view of the implant-tooth supported screw-cement retained prosthesis 10 years postcementation. Note absence of mesial contact on tooth \#23 and erythematous gingival margins. Crown for tooth \#23 was remade to re-establish contact points and marginal adaptation. Multi-unit abutments were further polished.

\section{Clinical case 2}

A 60-year-old female presented to the CEPID for prosthetic treatment of the lower right quadrant. Clinical exam revealed presence of only the anterior teeth in the lower right quadrant. Tooth \#27 showed previous endodontic treatment. Patient was scheduled for placement of 2 external-hexed implants of $3.75 \mathrm{x}$ $8.5 \mathrm{~mm}$ (Sistema de implante Conexao, SP, Brazil) for teeth \#28 and 30. Implant \#28 failed to osseointegrate; therefore, it was planned to proceed with a tooth-implant supported bridge connecting tooth \# 27 to implant \#30.

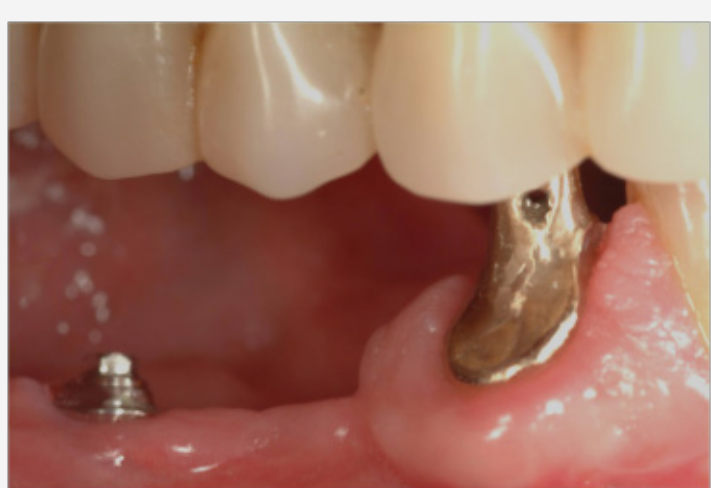

Figure 7: Multi-unit abutment for implant \#30 and gold alloy cast core for tooth \#27 with a screw access hole for a retaining screw.

Root canal therapy was conducted for tooth \#27. A multi-unit abutment was secured to implant \#30 and an impression was made. A post and core that covered the entire surface of remaining 
root \#27 was fabricated with a gold alloy. The core was fabricated to receive a prosthetic retaining screw, similar to the previous case. The entire prosthetic process described above was repeated in this case (Figures 7-9). Clinical recall exam showed prosthetic survival and healthy tissue (Figures 10,11).

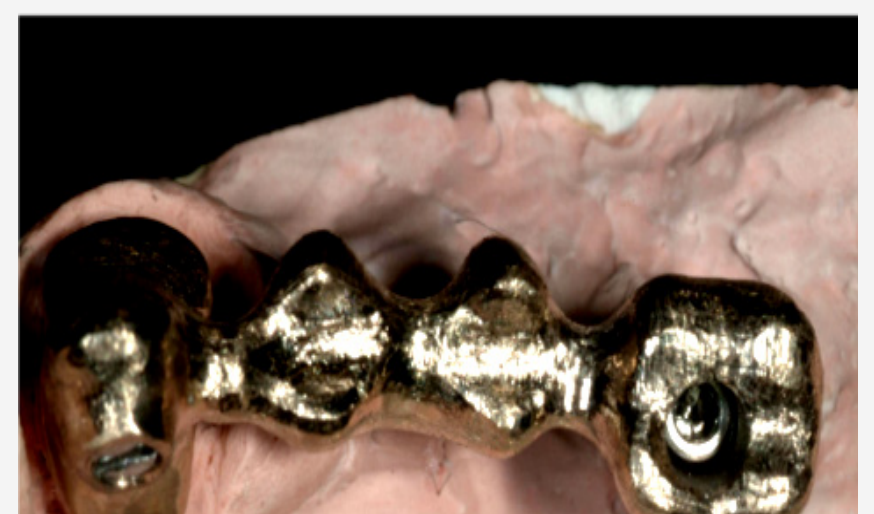

Figure 8: Occlusal view of the gold alloy infrastructure. Note presence of the lingual access hole on tooth \#27 and occlusal access hole for implant \#30.

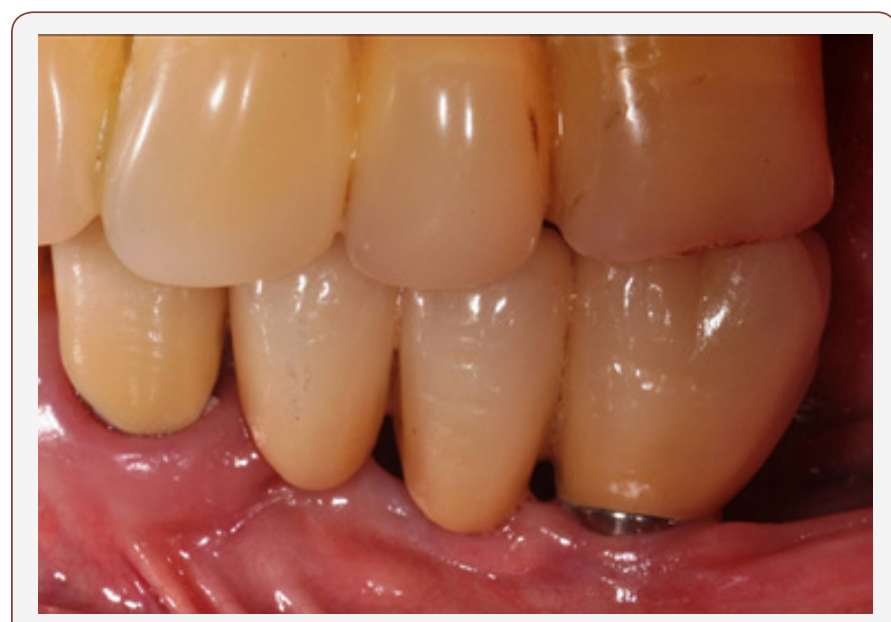

Figure 9: Porcelain-fused to metal bridge fabricated and installed.

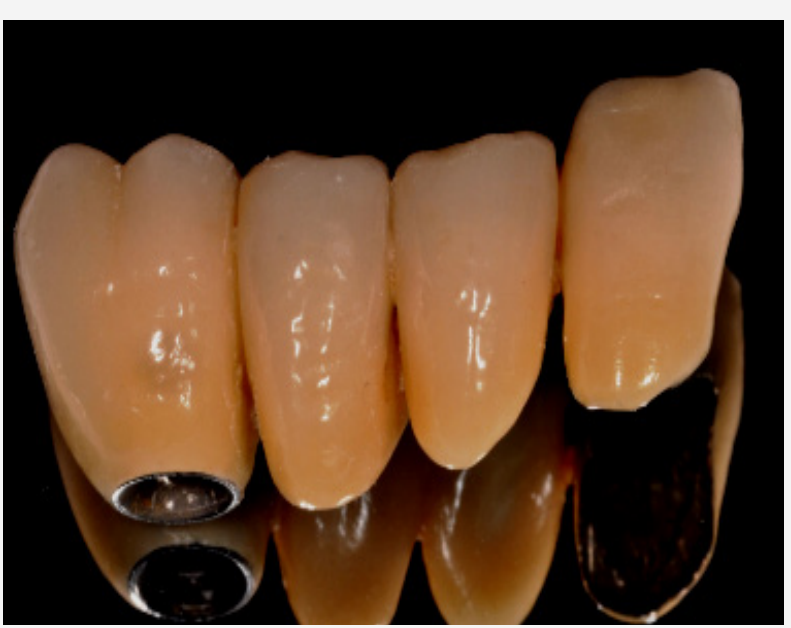

Figure 10: Porcelain-fused to metal bridge removed for 8 -year maintenance. Note presence of slight amounts of interproximal calculus but absence of prosthetic failure.

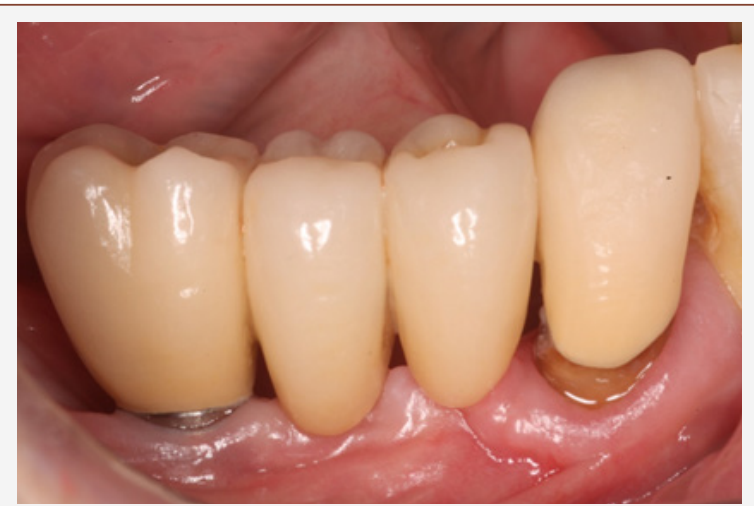

Figure 11: Clinical buccal view of the 4-unit implant-tooth supported prosthesis at the 8-year maintenance visit after prosthetic re-attachment. Note presence of healthy tissues as well as gingival retraction at \#27.

\section{Discussion}

Tooth-implant-supported prostheses are subject to many of the same risk factors as conventional prostheses. Lindhe et al [8] \& Gune et al [9] studied the union of teeth and implants with rigid connectors, using a modified system or custom fit locking screws and cement retained crowns to natural teeth. No change in tooth mobility or any signs of intrusion of the abutment teeth were seen in any of these sample studies after 2 and 10 years in function $[8,9]$. Furthermore, in a study conducted by Cavicchia \& Bravi [10], the intrusion of the teeth were observed in two cases of implants connected to natural dentition. However, in both cases, the connection was semi-rigid and without the locking screw.

A retrospective study of precision rigid connectors used to connect implant to natural teeth showed that the abutment teeth had intruded and presented fracture of the locking screw that promoted the structural stiffness. The breaking of the cement seal occurred in two natural abutments. Still, the prostheses showed no differences in marginal natural abutments despite an almost complete washout of the temporary cement. These results indicate that for intrusion of the tooth to occur, a certain freedom of movement between the tooth and the prosthesis must exist [5]. In the present clinical cases reported, screw retention was used to attach the prostheses to the natural abutment teeth and to the dental implants. This mechanism promotes $\backslash$ rigidity between the natural and implant abutments, reducing the possibility of decementation of crown and consequent movement between the abutments, which could ultimately result in dental intrusion.

Although several non-rigid connectors have been proposed to compensate the different degrees of mobility between the implant and tooth, clinical observations do not justify their function [4]. When the load is applied on the abutment tooth the implant abutment is overloaded [3]. This mechanism is confirmed by photo elasticity and finite element analysis, where it was shown that the implant abutment receives the greater stress in relation to the tooth abutment, indicating that the prosthesis is supported primarily by implants. This tension is aggravated by increasing the number of pontics [19].

Other clinical studies have demonstrated favorable success with tooth-implant supported partial dentures and show similar 
or even lower marginal bone loss around implants compared with treatments with implant supported fixed partial dentures [822]. Other studies show intrusion of abutment teeth using rigid connectors. In addition, bone loss increased when comparing rigid and non-rigid connectors between teeth and implants [16].

The survival rates of tooth-implant supported fixed partial dentures vary between $85.1 \%$ and $95 \%$ [23]. Other authors found no difference in the survival rates of prosthetic tooth implant supported and implant supported restorations after periods 3.5 and 10 years [9-26].

There are several reports of fracture of the implant when attached to a natural tooth [23]. Examination of an implant using scanning electron microscopy shows streaks on its surface which are indicative of fatigue failure as a result of poor biomechanics [25]. The planning of prosthetic rehabilitations should preferably include only implant-supported prostheses. Clinical limitations or patient preferences may suggest a combination treatment whereby fixed partial dentures are supported by implants and teeth. In this treatment modality, the authors concur with the literature [20] and suggest the use of rigid connection between the implant and the natural tooth abutments.

\section{Final Considerations}

All Implant supported or all tooth supported fixed dental prostheses are the first treatment option to replace lost teeth; however, there are limitations that may restrict this treatment modality. In these cases, implant-tooth supported prostheses are presented as predictable treatment options that may show a prognosis similar to the implant-supported and traditional dentalsupported prostheses.

\section{Acknowledgements}

The authors would like to thank the laboratory technician, $\mathrm{Mr}$. Jose Luis Batista, for the fabrication of the prostheses presented in this case presentation.

\section{References}

1. Ozçelik T, Ersoy AE (2007) An investigation of tooth/implant-supported fixed prosthesis designs with two different stress analysis methods: an in vitro study. J Prosthodont 16(2): 107-116

2. Cohen SR, Orenstein JH (1994) The use of attachment in combination implant and natural tooth fixed partial dentures: a technical report. Int ] oral Maxillofac Implants 2(9): 230-234.

3. Kayacan R, Ballarini R, Mullen RL (1997) Theoretical study of the effects of tooth and implant mobility differences on occlusal force transmission in tooth/implant-supported prostheses. J Prosthet Dent 78: 677-681.

4. Nishimura RD, Ochiai KT, Caputo AA, Jeong CM (1999) Photoelastic stress analysis of load transfer to implants and natural teeth comparing rigid and semirigid connectors. J Prosthet Dent 81(6): 696-703.

5. Fugazzotto PA, Kirsch A, Ackermann KL, Neuendorff G (1999) Implant/ tooth-connected restorations utilizing screw-fixed attachments: a survey of 3,096 sites in function for 3 to 14 years. Int J Oral Maxillofac Implants 14(6): 819-823.

6. Bader JD, Rozier RG, McFall WT Jr, Ramsey DL (1991) Effect of crown margins on periodontal conditions in regularly attending patients. J Prosthet Dent 65(1): 75-79.

7. Ramfjord SP (1984) Periodontology and restorative dentistry 2. Phillip J Restaur Zahnmed 1(3): 163-170.
8. Lindh T, Back T, Nystrom E, Gunne J (2001) Implant versus tooth-implant supported prostheses in the posterior maxilla: a 2-year report. Clin Oral Implants Res 12(5): 441-449.

9. Gunne J, Astrand P, Lindh T, Borg K, Olsson M (1999) Tooth-implant and implant supported fixed partial dentures: a 10-year report. Int J Prosthodont 12(3): 216-221

10. Cavicchia F, Bravi F (1994) Free-standing vs tooth connected implantsupported fixed partial restorations: a comparative retrospective clinical study of the prosthetic results. International Journal of Oral and Maxillofacial Implants 9(6): 711-718.

11. Ericsson I, Lekholm U, Brånemark PI, Lindhe J, Glantz PO, et al. (1986) A clinical evaluation of fixed-bridge restorations supported by the combination of teeth and osseointegrated titanium implants. J Clin Periodontol 13: 307-312

12. Naert I, Quirynen M, van Steenberghe D, Darius P (1992) A six-year prosthodontic study of 509 consecutively inserted implants for the treatment of partial edentulism. J Prosthet Dent 67(2): 236-245.

13. Weinberg LA, Kruger B (1994) Biomechanical considerations when combining tooth-supported and implant-supported prostheses. Oral Surg Oral Med Oral Pathol 78(1): 22-27.

14. Garcia LT, Oesterle LJ (1998) Natural tooth intrusion phenomenon with implants: a survey. Int J Oral Maxillofac Implants 13(2): 227-231.

15. Naert IE, Duyck JA, Hosny MMF, van Steenberghe D (2001) Freestanding and tooth-implant connected prostheses in the treatment of partially edentulous patients part I: an up to 15 years clinical evaluation. Clin Oral Implants Res 12(3): 237-244.

16. Kindberg H, Gunne J, Kronström M (2001) Tooth-and implant-supported prostheses: a retrospective clinical follow-up up to 8 years. Int J Prosthodont 14(6): 575-581.

17. Keller D, Hammerle CHF, Lang NP (1996) Thresholds for tactile sensitivity perceived with dental implants remain unchanged during a healing phase of 3 months. Clin Oral Implants Res 7(1): 48-54.

18. Block MS, Lirette D, Gardiner D, Li L, Finger IM, et al. (2002) Prospective evaluation of implants connected to teeth. Int J Oral Maxillofac Implants 17(4): 473-487.

19. Lindh T, Gunne J, Tillberg A, Molin M(1998) A meta-analysis of implants in partial edentulism. Clin Oral Implants Res 9(2): 80-90.

20. Lang NP, Pjetursson BE, Tan K, Bragger U, Egger M, et al. (2004) A systematic review of the survival and complication rates of fixed partial dentures (FPDs) after an observation period of at least 5 years. II. Combined tooth-implant-supported FPDs. Clin Oral Impl Res 15(6): 643-653.

21. Hebel KS, Gajjar RC (1997) Cement-retained versus screw-retained implant restorations: achieving optimal occlusion and esthetics in implant dentistry. J Prosthet Dent 77(1): 28-35.

22. Palmer RM, Howe LC, Palmer PJ (2005) A prospective 3-year study of fixed bridges linking Astra Tech ST implants to natural teeth. Clin Oral Implants Res 16(3): 302-307.

23. Pjetursson BE, Tan K, Lang NP, Bragger U, Egger M, et al. (2004) A systematic review of the survival and complication rates of fixed partial dentures (FPDs) after an observation period of at least 5 years. Clin Oral Implants Res 15(6): 625-642.

24. Bragger U, Aeschlimann S, Burgin W, Hammerle CHF, Lang NP (2001) Biological and technical complications and failures with fixed partial dentures (FPD) on implants and teeth after four to five years of function. Clin Oral Implants Res 12(1): 26-34.

25. Bragger U, Karoussis I, Person R, Pjetursson BE, Salvi G, et al. (2005) Technical and biological complications/failures with single crowns and fixed partial dentures on implants: a 10-year prospective cohort study. Clin Oral Implants Rese 16(3): 326-334.

26. Olsson M, Gunne J, Astrand P, Borg K (1995) Bridges supported by freestanding implants versus bridges supported by tooth and implant. A five-year prospective study. Clin Oral Implants Res 6(2): 114-121. 